\title{
Prospectively measured lifestyle factors and BMI explain differences in health-related quality of life between colorectal cancer patients with and without comorbid diabetes
}

\author{
Pauline A. J. Vissers ${ }^{1,2}$ • Melissa S. Y. Thong ${ }^{1,2}$ • Frans Pouwer $^{1}$ • Geert-Jan Creemers ${ }^{3}$ • \\ Gerrit D. Slooter ${ }^{4}$ Lonneke V. van de Poll-Franse ${ }^{1,2}$
}

Received: 8 September 2015 / Accepted: 7 December 2015 / Published online: 30 December 2015

(C) The Author(s) 2016. This article is published with open access at Springerlink.com

\begin{abstract}
Purpose This study aimed to assess the longitudinal association between lifestyle factors, body mass index (BMI), and health-related quality of life (HRQoL) among colorectal cancer patients with $(\mathrm{CRCDM}+)$ and without diabetes (CRCDM-).

Methods Data from a longitudinal study among CRC patients diagnosed between 2000 and 2009 were used. Clinical characteristics were retrieved from the Netherlands Cancer Registry and questionnaires were sent in 2010, 2011, and 2012 using the Patient Reported Outcomes Following Initial Treatment and Long term Evaluation of Survivorship (PROFILES) registry. Lifestyle (including moderate-to-vigorous physical activity (MVPA), smoking and alcohol use), BMI, diabetes status, and HRQoL were assessed in the questionnaire.

Results One thousand seven hundred thirty-nine (49\%) patients responded to $\geq 2$ questionnaires, of whom $126 \mathrm{CRCDM}+$ and $789 \mathrm{CRCDM}-$ patients were included. CRCDM+ patients
\end{abstract}

Pauline A. J. Vissers

p.vissers@iknl.nl

1 CoRPS - Center of Research on Psychology in Somatic diseases, Department of Medical and Clinical Psychology, Tilburg University, P.O. Box 90153, 5000 LE Tilburg, The Netherlands

2 Netherlands Comprehensive Cancer Organisation, Utrecht, The Netherlands

3 Department of Internal Medicine, Catharina Hospital, Eindhoven, The Netherlands

4 Department of Surgery, Maxima Medical Centre, Veldhoven, The Netherlands had a higher BMI $\left(29.1 \pm 4.2\right.$ vs. $\left.26.4 \pm 3.7 \mathrm{~kg} / \mathrm{m}^{2}\right)$, whereas the number of alcohol users was lower (50 vs. $70 \%, p$ value $<0.0001$ ) among $\mathrm{CRCDM}+$ as compared to CRCDM- patients. Analyses adjusted for sociodemographic and cancer characteristics showed that $\mathrm{CRCDM}+$ patients reported statistically significantly lower physical function (beta $=-5.76$; $\mathrm{SE}=1.67$ ), global QoL (beta $=-4.31 ; \mathrm{SE}=1.48$ ), and more symptoms of fatigue (beta $=5.38 ; \mathrm{SE}=1.95$ ) than $\mathrm{CRCDM}-$ patients. However, these effects disappeared after adjustments for lifestyle factors and BMI which were all significant predictors of HRQoL. Additional adjustment for comorbidity further attenuated the main effect of DM on HRQoL.

Conclusions Diabetes was not independently associated with HRQoL but deteriorated HRQoL among CRCDM+ patients seem to be explained by an unhealthier lifestyle and other comorbid conditions. Moreover, residual confounding cannot be ruled out.

Keywords Colorectal cancer · Diabetes $\cdot$ Lifestyle · Health-related quality of life

\section{Introduction}

Nowadays, the number of patients with several chronic diseases or comorbidity is increasing due to the increased life expectancy and aging of the population [1]. Both cancer and diabetes are common chronic diseases and were among the leading causes of death worldwide in 2008, with 7.6 and 1.3 million deaths due to cancer and diabetes, respectively [2]. Among cancer patients, diabetes is one of the most frequently observed comorbidities with a prevalence of $14 \%$ among colorectal cancer (CRC) patients [3]. Previous literature shows that patients with diabetes have an increased risk to develop 
CRC [4], and that patients with both CRC and diabetes have about a $30 \%$ higher mortality risk [5]. Beside these poorer prognostic outcomes, studies also indicate that patients with both cancer and diabetes have a poorer health-related quality of Life (HRQoL) [6-10].

Previous studies mainly reported a lower general HRQoL $[6,9]$, physical function or mobility [7, 10] and vitality [9] among cancer patients with diabetes, compared to cancer patients without diabetes. However, the majority of these studies focused on prostate cancer patients $[8,9,11,12]$ and had a cross-sectional study design [6, 7, 9-11]. More importantly, only three studies adjusted their analyses for lifestyle factors $[6,8,10]$, of which two only included body mass index (BMI) and no other lifestyle factors such as physical activity, smoking, or alcohol use $[8,10]$.

Lifestyle factors have been shown to be important predictors of HRQoL among both CRC and diabetes patients. Several studies show that an increasing number of healthy lifestyle factors are associated with better HRQoL scores among CRC patients [13-15] as well as among diabetes patients [16]. Regarding the independent effect of lifestyle factors, two longitudinal studies among CRC patients showed that physically active (i.e., at least $150 \mathrm{~min} /$ week) patients reported a higher general HRQoL as compared to patients who were insufficiently active or inactive $[17,18]$. Another cross-sectional study from the UK reported that CRC patients who are physically active and have a moderate alcohol intake reported better functioning and lower levels of fatigue compared to those who did not consume alcohol [13]. No significant association between smoking and HRQoL was found [13]. In contrast, analyses of the Women's Health Study showed that persistent smoking among women with breast, colorectal, and endometrial cancer were more likely to report poor physical function, poor mental health, and lower role emotional function as compared to non-smoking patients [19]. Among diabetes patients, similar associations between lifestyle and HRQoL were found. Two cross-sectional studies showed that physical activity was positively associated, whereas BMI was negatively associated with both physical and mental health $[20,21]$. Smoking was less often studied, but a large study $(n=16$, 428) from the USA showed that patients who were not smoking were less likely to report a poor or fair health $(\mathrm{OR}=0.71 ; 95 \%$ CI $0.56-0.89)$ [16].

As $\mathrm{CRC}$ patients with diabetes $(\mathrm{CRCDM}+)$ are expected to have a poorer lifestyle than CRC patients without diabetes $\left(\mathrm{CRCDM}^{-}\right)$, these poorer lifestyle behaviors might explain the poorer HRQoL found among CRCDM+ vs. CRCDMpatients [6-10]. Moreover, prospective studies on differences in HRQoL between CRCDM+ and CRCDM- patients are missing. Therefore, this study aims to assess differences between CRCDM+ and CRCDM- patients in (1) lifestyle, (2) HRQoL measured prospectively, and (3) to assess whether lifestyle factors explain the differences in HRQoL between
$\mathrm{CRCDM}+$ and $\mathrm{CRCDM}-$ patients. As the main focus of this study was to assess the effect of individual lifestyle factors on HRQoL longitudinally, we confined the analyses to the independent lifestyle effects and did not include a composite lifestyle score. We hypothesize that $\mathrm{CRCDM}+$ patients have a poorer lifestyle and lower HRQoL as compared to CRCDM - patients.

\section{Methods}

\section{Setting and study population}

Data from a large population-based study among CRC patients were used. All CRC patients diagnosed between January 2000 and June 2009 were sampled from the southern area of the Netherlands Cancer Registry (NCR). The NCR contains clinical data on all newly diagnosed cancer patients in the Netherlands. The southern area comprises 2.4 million inhabitants, 10 hospitals, and 2 radiotherapy institutes. After the initial patient selection, the Patient Reported Outcomes Following Initial Treatment and Long term Evaluation of Survivorship (PROFILES) registry was used for the longitudinal patient reported data collection [22]. Patients with cognitive impairments, unverifiable addresses, and patients who died prior to the study start were excluded from the initial selection. The remaining CRC patients were invited to participate in 2010 (T1), 2011 (T2), and 2012 (T3). Ethical approval for the study was obtained from a local certified Medical Ethics Committee of the Maxima Medical Centre Veldhoven. A complete overview of the selection process can be found elsewhere [17]. The primary objective of this longitudinal study was to identify the HRQoL and health-care use of long-term CRC survivors and relate the outcomes to patient and cancer characteristics. For this secondary analysis, we only included CRC patients who were less than 5 years after cancer diagnosis when they completed their first questionnaire. This cut-off was chosen as previous research shows that patients change their lifestyle shortly after cancer diagnosis [23]. Thus, we expect to see most changes in lifestyle as well as in HRQoL within 5 years after diagnosis. Moreover, CRC patients with unknown diabetes status ( $n=5)$ or those who developed diabetes after completion of the first questionnaire $(n=16)$ were excluded from this analyses. Data from this longitudinal study are (partly) available online for noncommercial scientific research, subject to study question, privacy and confidentiality restrictions, and registration from PROFILES (www. profilesregistry.nl).

\section{Data collection}

CRC patients were invited for participation via the PROFILES registry and a letter from their (ex-) attending specialist 
to inform them of the study. The letter included a secured link with login and password to the online questionnaire, or patients could request a paper version of the questionnaire via a reply card, whichever they preferred. After 2 months, a reminder with a paper questionnaire was sent. Patients were reassured that nonparticipation had no consequences for their follow-up care or treatment.

\section{Diabetes status, sociodemographic, and clinical characteristics}

Diabetes status was self-reported using the self-administered comorbidity questionnaire [24]. Patients filled out whether they had diabetes in the past year or currently. Patients who reported having diabetes at the first questionnaire were classified as having diabetes. No distinction was made between type 1 and 2 diabetes. Month and year of diabetes diagnosis were reported only at T2. Similarly, the SCQ was used to assess comorbidities other than diabetes, including heart disease, high blood pressure, stroke, lung disease, anemia, kidney disease, stomach disease, liver disease, thyroid disease, depression, arthrosis, rheumatoid arthritis, and back pain. Age, gender, and clinical information including cancer diagnosis date, primary cancer treatment, and cancer stage were derived from the NCR. Moreover, patients reported their educational level which was categorized as low (no/primary school), medium (lower general secondary education/vocational training), or high (pre-university education/high vocational training/university) educational level.

\section{Lifestyle measures}

Lifestyle measures were self-reported in the questionnaires and include smoking, alcohol use, height and weight, and physical activity. Both smoking and alcohol were assessed as (1) never, (2) former, and (3) current use. Number of cigarettes smoked per day and glasses of alcohol drunk per week were also reported. However, as the number of smokers and current alcohol users among $\mathrm{CRCDM}+$ patients was low (i.e., $n=13$ and $n=70$ of the 126 included CRCDM+ patients, respectively), no measure of moderate and heavy drinking or smoking was included. Self-reported body height and weight were used to calculate BMI. Physical activity was measured using questions derived from the validated European Prospective Investigation into Cancer (EPIC) physical activity questionnaire [25]. Patients filled out how much time they spent on walking, cycling, gardening, household activities and sports, six different sport types could be specified, during winter and summer. The mean scores for all activities during winter and summer were averaged. To assess the intensity, metabolic equivalent intensity (MET) scores based on previous classifications were assigned to each activity [26, 27]. Hours per week spent on moderate to vigorous physical activity
(MVPA) were calculated by summing all activities with a MET-score $\geq 3$ and include walking $(\mathrm{MET}=3.5)$, cycling $(\mathrm{MET}=4)$, gardening $(\mathrm{MET}=5)$, and various sports with a MET-score $\geq 3$. Household activities $(\mathrm{MET}=3.5)$ were not considered as MVPA in accordance with previous research [28]. To correct for outliers, all activity scores greater than the 95 th percentile were replaced by the 95 th percentile.

\section{Health-related quality of life}

The validated European Organisation for Research and Treatment of Cancer-Quality of Life Questionnaire (EORTCQLQ)-C30 was used to assess HRQoL [29, 30]. As previous research shows that cancer patients with diabetes mainly score lower on physical function $[7,10,11]$, general HRQoL $[6,9]$, and vitality [9] as compared to those without diabetes, and to prevent type 1 errors as a result of multiple testing, only the global QoL, physical function, and fatigue scales were included in these analyses. All items were answered on a 4-point Likert scale ranging from 'not at all' to 'very much', while the questions regarding global QoL were scored on a 7-point scale. Item scores were linearly transformed to a 1 to 100 scale. Higher scores on global QoL and physical function represent better functioning, while a higher score on fatigue symptoms correspond to more fatigue.

\section{Statistical analyses}

Differences in characteristics between respondents and nonrespondents at $\mathrm{T} 1$, between patients who completed 1 vs. those who completed $\geq 2$ questionnaires, and $\mathrm{CRCDM}+$ and CRCDM- patients of the final study sample were analyzed. Continuous variables were checked for normality. If variables were normally distributed, the independent samples $t$ tests were used. Otherwise, the nonparametric Wilcoxon-MannWhitney test was used to assess differences between the groups. The chi-square test was used for categorical variables.

First, differences in BMI and MVPA between CRCDM+ and CRCDM- patients at each time point were assessed with independent samples $t$ tests. Smoking and alcohol status over time was recoded into one categorical variable with four categories: persistent smokers/alcohol users, persistent former smokers/alcohol users, persistent non-smokers/alcohol users, and patients with fluctuating smoking/alcohol status. Patients were assigned to the persistent categories when they reported the same category on all questionnaires; otherwise, they were included in the fluctuating status category. Differences in smoking and alcohol category between $\mathrm{CRCDM}+$ and CRCDM- patients were assessed with chi-square tests.

In order to gain insight into the differences in HRQoL between CRCDM+ and CRCDM- patients with different lifestyle behaviors, we reported unadjusted means of physical function, global QoL, and fatigue stratified by diabetes status 
for each lifestyle factor measured at T1. To adjust for the dependence of observations within subjects, generalized linear mixed models, using an unstructured covariance structure, were constructed. First, differences in lifestyle factors between $\mathrm{CRCDM}+$ and $\mathrm{CRCDM}-$ patients over time were assessed in a model that included the main effects of DM, time, and the interaction between DM and time. When the interaction term was significant, the results for CRCDM+ and CRCDM- patients were stratified; otherwise, the interaction term was removed from the model in order to interpret the main effects of DM and time. Second, similar general linear mixed models were used to assess the main effects of DM and time on global QoL, physical function, and fatigue. Both models that addressed differences in lifestyle and HRQoL were adjusted for sociodemographic (age, sex, educational level) and clinical characteristics (time since cancer diagnosis, cancer stage, and treatment). Finally, the models predicting HRQoL were additionally adjusted for lifestyle factors to assess whether differences in HRQoL between CRCDM + and CRCDM- could be explained by lifestyle. To examine the independent between and within-subject effects of BMI and MVPA on HRQoL, two terms were included in the model; a between term, represented by a person's average BMI or MVPA over the two or three time points, as well as a within term, represented by the difference between a person's BMI or MVPA at one time point and that persons average BMI or MVPA over the two or three time points. The categorical variables (i.e., persistent and fluctuating use) for both smoking and alcohol use were included in the generalized linear mixed models. The continuous variables (i.e., age and time since cancer diagnosis) were grandmean centered in order to correctly interpret all model parameters. Moreover, as we expect that cancer patients with diabetes have more comorbid conditions other than diabetes and as comorbidity has previously been shown to impact on HRQoL among cancer patients [31], we conducted a sensitivity analyses to see whether comorbidity other than diabetes explains the differences in HRQoL (i.e., beyond lifestyle factors) between $\mathrm{CRCDM}+$ and $\mathrm{CRCDM}-$ patients. As information on the duration of diabetes at the study start was available for a subsample, we assessed whether there were differences between CRCDM+ with a diabetes duration $<6.5$ years and $\geq 6.5$ years vs. CRCDM- patients in a sub-analysis. This cut-off was based on the median diabetes duration.

A $p$ value $<0.05$ was regarded as statistically significant and all analyses were conducted using SAS statistics version 9.3 (SAS Institute, Inc., Cary, NC).

\section{Results}

\section{Patient selection process}

Of the 3585 eligible CRC patients, 2625 (73\%) responded to the first questionnaire and $1739(49 \%)$ responded to $\geq 2$ questionnaires. After excluding patients who were $\geq 5$ years after cancer diagnosis, patients with an unknown diabetes status $(n=5,1 \%)$ and those who developed diabetes during the study period ( $n=16,2 \%), 126 \mathrm{CRCDM}+$ and $789 \mathrm{CRCDM}$ - patients were included (Fig. 1). Full details of the studies selection process can be found online at http://www. profilesregistry.nl/dataarchive/study_units/view/22 under 'Data \& Documentation'. More details of the study process, the comparison of respondents with non-respondents, and the
Fig. 1 Flowchart of the study process

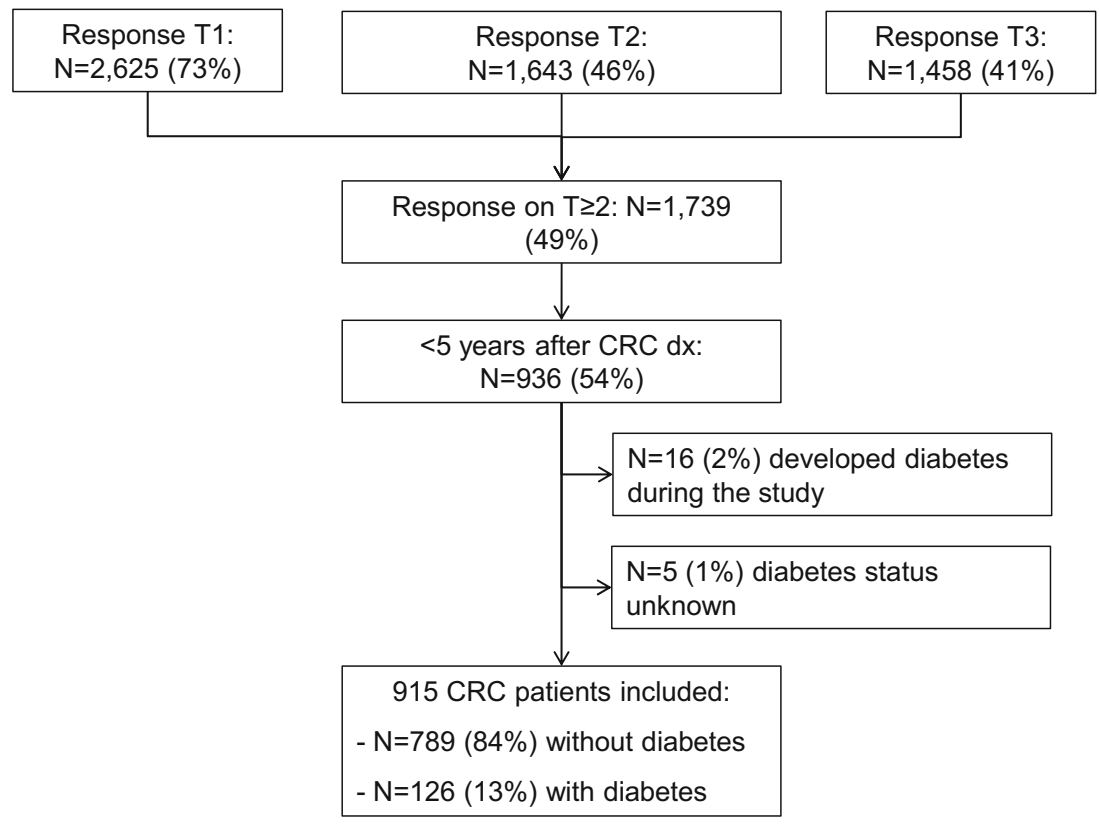


comparison of those who completed 1 vs. $\geq 2$ questionnaires are reported elsewhere [17]. In general, respondents at T1 were significantly younger, more often male, and more often diagnosed with stage I disease than non-respondents. CRC patients who completed $\geq 2$ vs. only 1 questionnaire were younger ( $68.4 \pm 9.4$ vs. $71.3 \pm 9.4$ years), less often female (43 vs. $49 \%$ ), and less often diagnosed with stage IV disease ( 3 vs. $7 \%$ ). Moreover, CRC patients who completed $\geq 2$ vs. 1 questionnaire were more likely to consume alcohol ( 73 vs. $61 \%$ ), were more physically active ( $12 \pm 9$ vs. $9 \pm 9$ h/ week spent on MVPA), and reported a higher global QoL (79 \pm 18 vs. $73 \pm 21)$, higher physical function ( $82 \pm 19$ vs. $75 \pm$ $23)$, and lower fatigue levels ( $20 \pm 22$ vs. $26 \pm 26)$.

\section{Differences in characteristics and lifestyle factors over time between CRCDM+ and CRCDM-}

CRCDM+ patients were lower educated ( 24 vs. $14 \%$ with a low education) and had more comorbid conditions other than diabetes ( 50 vs. $35 \%$ with $\geq 2$ comorbid conditions other than diabetes, Table 1). Diabetes duration was available for $95(75 \%) \mathrm{CRCDM}+$ patients and $\mathrm{CRCDM}+$ patients were diagnosed with diabetes on average 8.3 \pm 7.2 years prior to the study start. No differences between CRCDM+ and CRCDM- patients were found on sex, age, cancer stage, time since cancer diagnosis, and cancer treatment.

$\mathrm{CRCDM}+$ patients had a significantly higher BMI at T1 $\left(29.1 \pm 4.2\right.$ vs. $\left.26.4 \pm 3.7 \mathrm{~kg} / \mathrm{m}^{2}\right)$, T2 $(28.6 \pm 4.3$ vs. 26.5 $\left.\pm 4.4 \mathrm{~kg} / \mathrm{m}^{2}\right)$, and T3 $\left(29.1 \pm 4.1\right.$ vs. $26.4 \pm 3.9 \mathrm{~kg} / \mathrm{m}^{2}$, all $p$ values $<0.0001$, Fig. $2 \mathrm{a}$ ). In adjusted generalized linear mixed models, no interaction of DM*time was found, indicating that BMI did not differ between both groups over time. After removing the interaction term, a main effect for diabetes (beta $=2.44 ; \mathrm{SE}=0.35, p$ value $<0.0001$ ) but not for time ( $p$ value $=0.06)$ on BMI was observed. No difference between CRCDM+ and CRCDM- in MVPA at T1 $(p$ value $=0.07), \mathrm{T} 2(p$ value $=0.27)$, or T3 $(p$ value $=0.59)$ was observed (Fig. 2b). Again, no interaction between DM and time was observed, indicating that MVPA did not differ between both groups over time. No main effect of DM was observed while MVPA did significantly change over time $(p$ value $=0.01)$. Although, there were slightly more $\mathrm{CRCDM}+$ patients who persistently reported to be ex-smokers (63 vs. $53 \%$ ), no overall difference in smoking status between CRCDM+ and CRCDM- was observed ( $p$ value $=0.09$ ). However, among $\mathrm{CRCDM}+$, there were fewer patients who persistently reported to use alcohol (50 vs. $70 \%, p$ value $<0.0001)$. Both smoking and alcohol status were quite stable over time with $8 \%(n=77)$ and $13 \%$ $(n=126)$ reporting fluctuating smoking and alcohol status during the study period, respectively.
Table 1 Sociodemographic and clinical characteristics (T1) of the study population

\begin{tabular}{|c|c|c|c|}
\hline$n(\%)$ or mean $\pm \mathrm{SD}$ & $\begin{array}{l}\text { CRCDM+ } \\
n=126\end{array}$ & $\begin{array}{l}\text { CRCDM- } \\
n=789\end{array}$ & $p$ value \\
\hline Male & $80(63)$ & $453(57)$ & 0.2 \\
\hline Age (years) & $70 \pm 8$ & $68 \pm 10$ & $0.06^{\mathrm{b}}$ \\
\hline \multicolumn{4}{|l|}{ Educational level $^{\mathrm{a}}$} \\
\hline Low & $30(24)$ & $113(14)$ & \multirow[t]{3}{*}{0.02} \\
\hline Medium & $73(58)$ & $488(62)$ & \\
\hline High & $23(18)$ & $184(23)$ & \\
\hline \multicolumn{4}{|l|}{ Comorbidity other than diabetes } \\
\hline 0 & $20(16)$ & $241(32)$ & \multirow[t]{3}{*}{0.0006} \\
\hline 1 & $42(34)$ & $251(33)$ & \\
\hline$\geq 2$ & $61(50)$ & $263(35)$ & \\
\hline \multicolumn{4}{|l|}{ Cancer stage } \\
\hline I & $38(30)$ & $218(28)$ & \multirow[t]{5}{*}{0.40} \\
\hline II & $41(33)$ & $264(33)$ & \\
\hline III & $41(33)$ & $236(30)$ & \\
\hline IV & $5(4)$ & $38(5)$ & \\
\hline Unknown & $1(1)$ & $33(4)$ & \\
\hline Time since diagnosis (years) & $3 \pm 1$ & $3 \pm 1$ & $0.16^{\mathrm{b}}$ \\
\hline Surgery & $124(98)$ & $785(99)$ & N/A \\
\hline Chemotherapy & $46(37)$ & $258(33)$ & 0.40 \\
\hline Radiotherapy & $36(29)$ & $262(33)$ & 0.3 \\
\hline Diabetes duration (years) & $8.3 \pm 7.2$ & & \\
\hline \multicolumn{4}{|l|}{ Diabetes duration - categorical } \\
\hline$<6.5$ years & 47 (37) & & \\
\hline$\geq 6.5$ years & $48(38)$ & & \\
\hline Unknown & $31(24)$ & & \\
\hline
\end{tabular}

$N / A$ no valid $p$ value could be obtained as the number of patients who did not receive surgery was too low (i.e., $2 \mathrm{CRCDM}+$ and $4 \mathrm{CRCDM}-$ patients) to conduct a valid chi-square test

${ }^{\mathrm{a}}$ Education levels included the following categories: low $=$ no/primary school, medium = lower general secondary education/vocational training, or high $=$ pre-university education/high vocational training/university

${ }^{\mathrm{b}}$ Statistical difference tested with the nonparametric Wilcoxon-MannWhitney test

\section{Differences in HRQoL and the impact of lifestyle on HRQoL among CRCDM+ and CRCDM- patients}

Physical function was lowest among CRCDM+ patients with BMI $\geq 30 \mathrm{~kg} / \mathrm{m}^{2}$ (mean at T1 $68 \pm 23$ ) and highest among CRC patients with BMI between $25-30 \mathrm{~kg} / \mathrm{m}^{2}$ (at $\mathrm{T} 1$ : both CRCDM- and CRCDM $+84 \pm 18$, Fig. 3). CRCDM- patients with $\geq 14 \mathrm{~h} /$ week MVPA reported highest physical function (at T1 89 \pm 14 ), whereas inactive CRC patients report the lowest physical function (at T1, CRCDM- $59 \pm 24$ and CRCDM+ patients $58 \pm 26$ ). $\mathrm{CRCDM}-$ and $\mathrm{CRCDM}+$ patients who never smoked reported highest physical function (at T1 $84 \pm 16$ and $76 \pm 19$, respectively), while smokers reported lowest 
Fig. 2 Differences in a BMI, b MVPA, c Smoking, and d alcohol use between CRCDM$(\boldsymbol{a})$ and $\mathrm{CRCDM}+(\square)$. **Significant difference between CRCDM+ and CRCDM - using independent samples $t$ test with $p$ value $<0.0001$. BMI body mass index, MVPA moderate-tovigorous physical activity
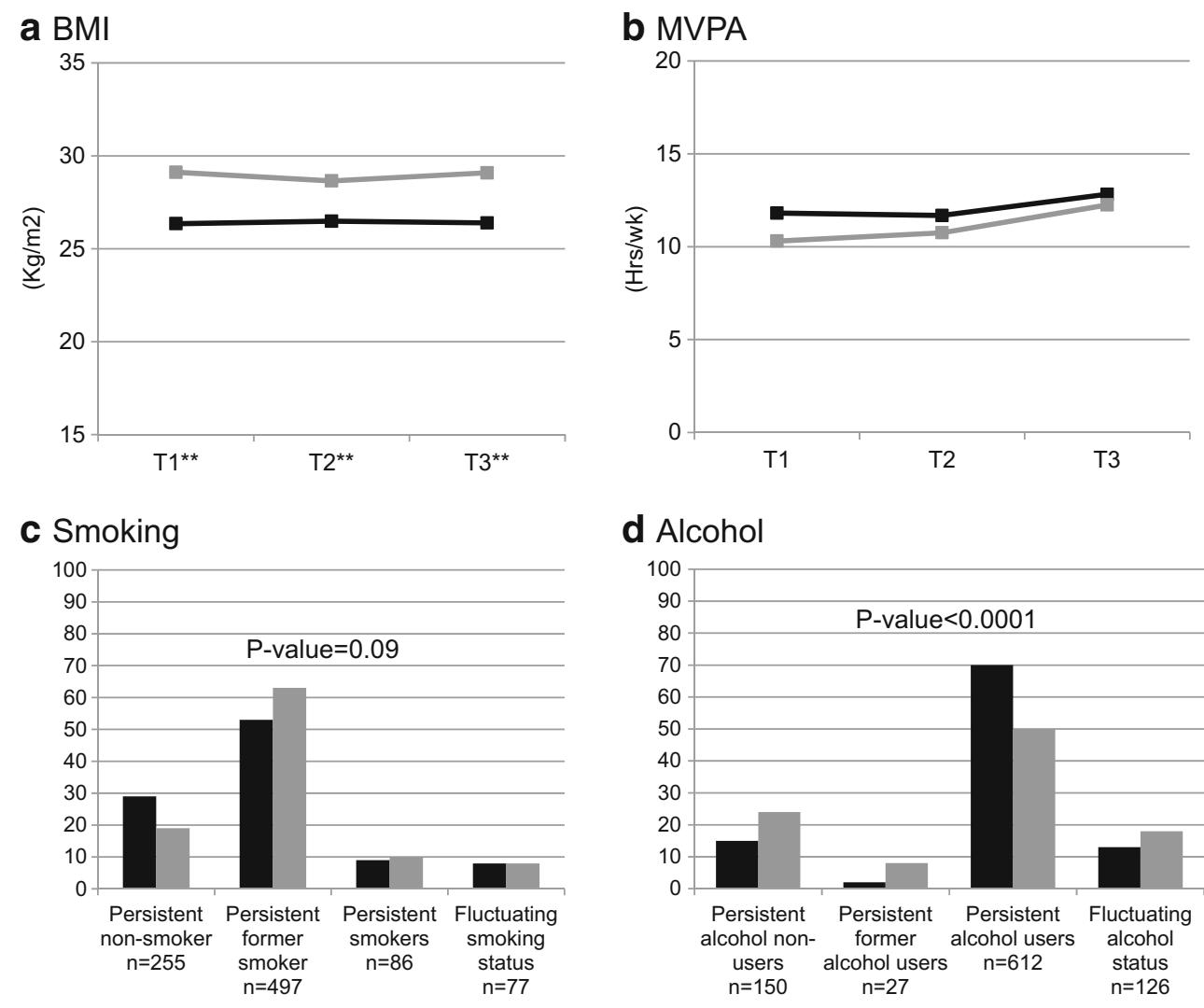

d Alcohol

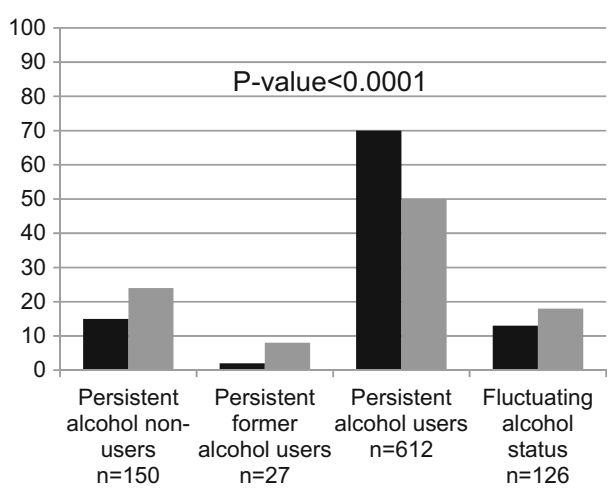

physical function with $78 \pm 19$ and $62 \pm 32$, respectively. Alcohol users reported higher physical function as compared to former or never users. For global QoL and fatigue, similar patterns were observed. In general, smokers, obese patients $\left(\mathrm{BMI} \geq 30 \mathrm{~kg} / \mathrm{m}^{2}\right.$ ) and inactive patients reported lowest QoL and most fatigue, while alcohol drinkers reported highest global QoL and lowest fatigue (data not shown).

In adjusted generalized linear mixed models, no interaction effect between DM and time was found on any of the HRQoL scales, meaning that HRQoL did not differ between CRCDM+ and CRCDM- patients over time. After removing the interaction term, CRCDM+ patients reported significantly lower physical function (beta $=-5.76$; $\mathrm{SE}=1.67$ ), global QoL (beta $=-4.31 ; \mathrm{SE}=1.48$ ), and more fatigue (beta $=5.38$; $\mathrm{SE}=1.95$ ) than $\mathrm{CRCDM}-$ patients. However, after additional adjustments for BMI, MVPA, smoking, and alcohol use the main effect of diabetes disappeared for all three subscales (Table 2, model 2). With each point increase in BMI, physical function decreased (beta $=-0.71$; SE 0.15 ), and symptoms of fatigue increased (beta $=0.47 ; \mathrm{SE}=0.18$ ). No within-subject effect of BMI was found, i.e., individual changes in BMI during the study period were not associated with changes in HRQoL. With each hour increase in MVPA per week, physical function (beta $=0.64 ; \mathrm{SE}=0.07$ ) and global QoL increased (beta $=0.35 ; \mathrm{SE}=0.07$ ) whereas symptoms of fatigue decreased (beta $=-0.50 ; \mathrm{SE}=0.09$ ). A within-subject effect was found for both physical function and fatigue indicating that when a person increased their MVPA with $1 \mathrm{~h}$ per week above their average MVPA during the study period, their physical function increased with 0.09 points $(\mathrm{SE}=0.04)$ and their fatigue score decreased with $0.15(\mathrm{SE}=0.06)$. Persistent smoking as compared to never smoking was associated with lower physical function and global QoL and more fatigue. In contrast, persistent drinking during the study period was associated with higher physical function and global QoL and less fatigue.

After additionally adjusting the full model 2 for comorbidity (i.e., 1 or $\geq 2$ vs. 0 comorbidity), the main effect of diabetes was attenuated even further for physical function (beta $\mathrm{DM}+$ vs. $\mathrm{DM}-=-0.85, \mathrm{SE}=1.56$ ), global $\mathrm{QoL}$ (beta $\mathrm{DM}+$ vs. $\mathrm{DM}-=-1.43, \mathrm{SE}=1.48$ ), and fatigue (beta $\mathrm{DM}+$ vs. $\mathrm{DM}-=1.11, \mathrm{SE}=0.56$ ). All lifestyle factors remained independently associated with HRQoL and estimates were similar to those presented in model 2, Table 2.

We also included diabetes duration and used a categorical variable including CRCDM - , CRCDM + with $<6.5$ years diabetes duration, $\mathrm{CRCDM}+$ with $\geq 6.5$ years diabetes duration and $\mathrm{CRCDM}+$ with unknown diabetes duration in the model. We found that in model $1 \mathrm{CRCDM}+$ with short diabetes duration (i.e., $<6.5$ years) was associated with worse global QoL (beta $=-5.02, \mathrm{SE}=2.32$ ) while longer term diabetes duration (i.e., $\geq 6.5$ years) was associated with lower physical function (beta $=-6.56, \mathrm{SE}=2.56$, data not shown). After adjustment for both lifestyle factors and comorbidity, these effects attenuated to non-significance. 

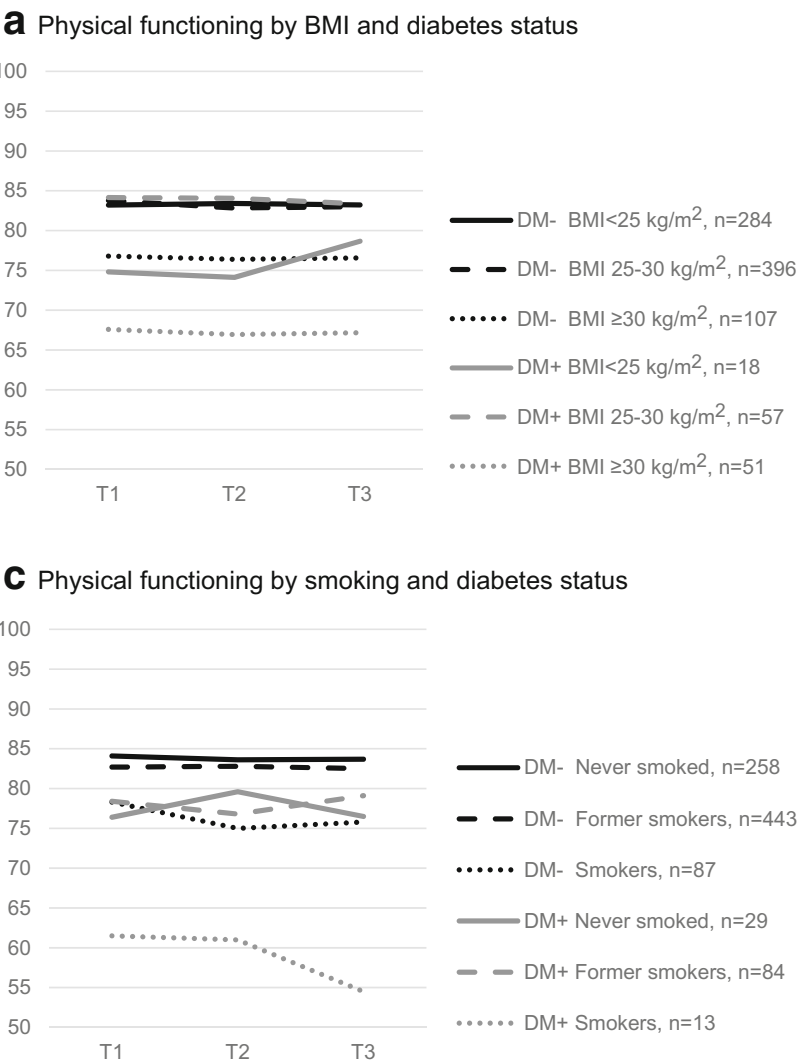

Fig. 3 Mean scores on physical function stratified by BMI and lifestyle factors (measured at T1) and diabetes status. a Physical functioning by BMI and diabetes status. b Physical functioning by MVPA and diabetes

\section{Discussion}

This study shows that CRCDM+ and CRCDM- differed regarding lifestyle behaviors; $\mathrm{CRCDM}+$ had a higher $\mathrm{BMI}$ and was less likely to consume alcohol. No differences in MVPA and smoking status between CRCDM+ and CRCDM- patients were observed. In addition, prospectively measured physical function and global QoL were lower, while fatigue was higher among CRCDM+ patients as compared to CRCDM- patients. However, these differences in HRQoL outcomes disappeared after adjusting for lifestyle factors; BMI, MVPA, smoking, and alcohol were all significant predictors of HRQoL. Further adjustment for comorbidity further attenuated the main effect of diabetes. This suggests that diabetes is not independently associated with HRQoL but that the found lower HRQoL scores among CRCDM+ patients seem to be explained by an unhealthier lifestyle and other comorbid conditions.

A few studies assessed HRQoL among cancer patients with and without diabetes and adjusted for lifestyle factors; two studies adjusted for BMI only $[8,10]$ and one study adjusted for BMI, physical activity, and smoking [6]. In line with our results, all three studies reported higher BMI among cancer patients with vs. without DM. Moreover, a large Canadian

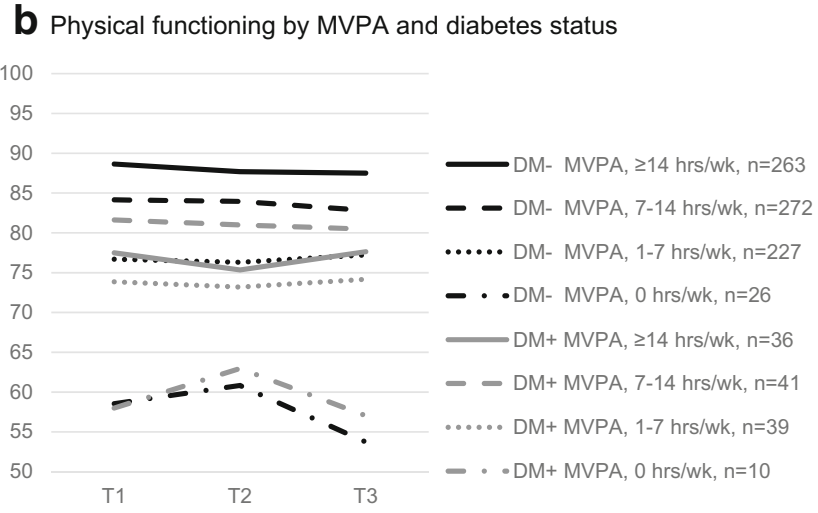

d Physical functioning by alcohol and diabetes status

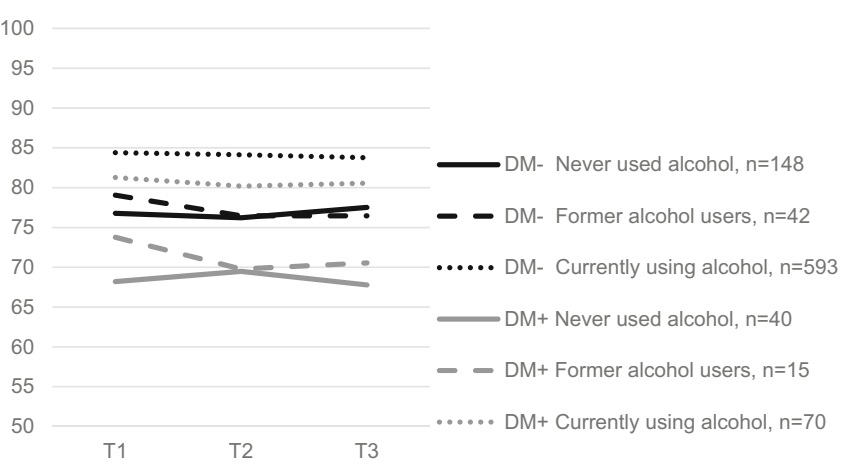

status. c Physical functioning by smoking and diabetes status. d Physical functioning by alcohol and diabetes status

cross-sectional study $(n=113,587)$ also reported lower physical activity (14 vs. $20 \%$ being active) and no clear differences in the frequency of smoking (18 vs. $16 \%$ ) between both groups [6]. In contrast to our results, after adjustment for BMI (and smoking), all three studies reported a lower HRQoL among cancer patients with vs. without diabetes $[6,8,10]$. The large Canadian cross-sectional study found a lower Health Utility Index-3 score among cancer patients with vs. without DM with beta $=-0.04(95 \%$ CI $-0.05 ;-0.03)$ [6]. A longitudinal study among prostate cancer patients $(n=1248)$ reported a lower urinary function among prostate cancer patients with vs. without diabetes, while no differences were found on other urinary and sexual function subscales [8]. In our previous cross-sectional study, we observed a lower physical function $($ beta $=-3.8)$ and more male sexual problems (beta $=9.4)$ among CRCDM+ vs. CRCDM- patients [10]. The different cancer types studied and the different measurements used in previous studies hamper comparison of the results. This study shows that besides BMI and smoking, MVPA and alcohol use were also independently associated with HRQoL and should be taken into account when comparing HRQoL between cancer patients with and without diabetes. Only adjusting for BMI might not be sufficient. Alcohol consumption was associated with better HRQoL which is in line with previous research 
Table 2 The results of generalized linear mixed models to assess the effect of diabetes and lifestyle factors on physical function, global quality of life, and fatigue

\begin{tabular}{|c|c|c|c|c|c|c|}
\hline & \multicolumn{2}{|c|}{ Physical function } & \multicolumn{2}{|c|}{ Global quality of life } & \multicolumn{2}{|l|}{ Fatigue } \\
\hline & $\begin{array}{l}\text { Model } 1 \\
\text { beta (se) }\end{array}$ & $\begin{array}{l}\text { Model } 2 \\
\text { beta (se) }\end{array}$ & $\begin{array}{l}\text { Model } 1 \\
\text { beta (se) }\end{array}$ & $\begin{array}{l}\text { Model } 2 \\
\text { beta (se) }\end{array}$ & $\begin{array}{l}\text { Model } 1 \\
\text { beta (se) }\end{array}$ & $\begin{array}{l}\text { Model } 2 \\
\text { beta (se) }\end{array}$ \\
\hline DM+ vs. DM- & $-5.76(1.67)^{*}$ & $-2.12(1.61)$ & $-4.31(1.48)^{*}$ & $-2.66(1.53)$ & $5.38(1.95)^{*}$ & $2.26(1.95)$ \\
\hline \multicolumn{7}{|l|}{ Time } \\
\hline T2 vs. T1 & $-0.95(0.71)$ & $-0.69(0.70)$ & $-2.67(0.75)^{*}$ & $-2.12(0.75)^{*}$ & $1.53(0.92)$ & $1.20(0.92)$ \\
\hline T3 vs. T1 & $-2.29(1.25)$ & $-1.82(1.19)$ & $-2.51(1.21)^{*}$ & $-2.60(1.21)^{*}$ & $2.30(1.55)$ & $1.67(1.52)$ \\
\hline \multicolumn{7}{|l|}{ BMI $\left(\mathrm{kg} / \mathrm{m}^{2}\right)$} \\
\hline Between $^{\mathrm{a}}$ & & $-0.71(0.15)^{* *}$ & & $-0.24(0.14)$ & & $0.47(0.18)^{*}$ \\
\hline Within $^{\mathrm{b}}$ & & $0.06(0.12)$ & & $-0.03(0.15)$ & & $0.22(0.17)$ \\
\hline \multicolumn{7}{|l|}{ MVPA (h/week) } \\
\hline Between $^{\mathrm{a}}$ & & $0.64(0.07)^{* *}$ & & $0.35(0.07)^{* *}$ & & $-0.50(0.09)^{* *}$ \\
\hline Within $^{\mathrm{b}}$ & & $0.09(0.04)^{*}$ & & $0.05(0.05)$ & & $-0.15(0.06)^{*}$ \\
\hline \multicolumn{7}{|l|}{ Smoking } \\
\hline Persistent former vs. never & & $-3.98(1.34)^{*}$ & & $-2.88(1.27)^{*}$ & & $2.66(1.63)$ \\
\hline Persistent current vs. never & & $-10.24(2.06)^{* *}$ & & $-5.52(1.95)^{*}$ & & $8.21(2.50)^{*}$ \\
\hline Fluctuating vs. persistent never & & $-5.55(2.16)^{*}$ & & $-3.01(2.06)$ & & $4.61(2.63)$ \\
\hline \multicolumn{7}{|l|}{ Alcohol } \\
\hline Persistent former vs. never & & $-4.27(3.59)$ & & $-0.98(3.40)$ & & $0.20(4.36)$ \\
\hline Persistent current vs. never & & $5.97(1.68)^{*}$ & & $3.98(1.60)^{*}$ & & $-7.01(2.06)^{*}$ \\
\hline Fluctuating vs. persistent never & & $3.72(2.05)$ & & $0.74(1.95)$ & & $-3.10(2.49)$ \\
\hline
\end{tabular}

Model 1: Model to assess main effects of diabetes and time on HRQoL adjusted for age, sex, time since cancer diagnosis, cancer stage (stage I, II, III vs. stage IV), cancer treatment (radiotherapy: yes/no and chemotherapy: yes/no), and educational level (medium and high vs. low educational level)

Model 2: Model 1 with additional adjustments for lifestyle factors

$B M I$ body mass index, MVPA moderate-to-vigorous physical activity

${ }^{*} p$ value $<0.05$

$* * p$ value $<0.0001$

${ }^{\text {a }}$ Between-subjects effects represented by the persons average over all time points

${ }^{\mathrm{b}}$ Within-subjects effects represented by the difference between the average at one time point and the persons average over all time points

[13]. We assume that the alcohol users in our study consumed moderate amounts which may be associated with fewer comorbid conditions such as cardiovascular disease. Vice versa patients with severe chronic disease might consume less alcohol. The results of the present study emphasize that health professionals still need to encourage and support cancer patients in improving their lifestyle behaviors. Besides, providing adequate information on behavior change, health professionals also have to consider attitudes and motivations [32].

In this study, no information on clinical data regarding diabetes diagnosis was available. However, we did have information regarding self-reported diabetes duration for $75 \%$ of the $\mathrm{CRCDM}+$ patients. One might expect that patients with a longer diabetes duration develop more complications which in turn lead to lower HRQoL. We showed that CRCDM+ with a diabetes duration $<6.5$ years had lower global QoL while $\mathrm{CRCDM}+$ patients with a diabetes duration $\geq 6.5$ years had a lower physical function as compared to CRCDM- patients.
These differences were attenuated after adjustments for comorbidity and lifestyle, similar as in the main analyses. The absence of a consistent pattern might be due to the stratification which resulted in a low number of patients per group.

As cardiovascular diseases and kidney diseases are common among patients with diabetes [33] and comorbidity is significantly associated with HRQoL [31], we additionally adjusted model 2 for comorbidity in a sensitivity analysis. We initially did not adjust for comorbidity as adjustment for both lifestyle factors and comorbidity might lead to an overadjusted model. From literature, we know that impaired glucose tolerance, insulin resistance, obesity, dyslipidemia, and hypertension co-occur more often than might expected by chance [34]. This group of risk factors is also known as the Metabolic syndrome [34]. Thus, the metabolic syndrome might be part of the causal pathway for the development of diabetes. As we had no information on the date of diagnosis of the other comorbid conditions, we cannot ascertain whether 
these conditions developed after, and possibly as a result of, diabetes.

Obesity, physical inactivity, smoking, and alcohol use are all risk factors for both CRC and diabetes [35]. Although these lifestyle factors might have influenced the development of both diabetes and cancer among patients in this study, our results show that changes in lifestyle habits can improve HRQoL after the diagnosis of both diseases: patients who increased their physical activity during the study period reported higher physical function and less symptoms of fatigue. Among cancer survivors, several lifestyle interventions focused on improving dietary habits, smoking cessation, or increasing physical activity show promising results [23]. Moreover, in recent years, interventions have also focused on increasing physical and emotional condition prior to cancer treatment [36]. These prehabilitation studies showed promising results regarding morbidity, mortality, length of hospital stay, and HRQoL [36]. However, sustainable long-term effects of these lifestyle and prehabilitation interventions are rarely studied. Thus, future studies should focus on the development of prehabilitation and lifestyle interventions that are effective on the long term.

This study has several limitations. First, no information regarding lifestyle and $\mathrm{HRQ}$ oL prior to cancer diagnosis were available. As data were collected 1 to 5 years after cancer diagnosis, patients might have adopted their lifestyle directly after diagnosis and prior to the data collection which could have influenced our results. In addition, no information regarding diet was available. Moreover, lifestyle factors were self-reported and may have been influenced by recall bias and social desirability. Previous research shows high correlations between self-reported and objectively assessed BMI; however, elderly ( $>60$ years) often overreport their height and as a result, BMI is underreported [37]. In addition, the patients included in these analyses are likely to be healthier as those with poorer health are less likely to participate in the study and to complete the follow-up questionnaires. As a result, absolute scores on HRQoL should be interpreted cautiously. However, we do not expect the found association to be different as patients who did not respond or completed the follow-up are likely to report both poorer lifestyle behaviors and poorer HRQoL. Moreover, no data regarding diabetes type (i.e., type 1 or type 2 ), severity, and complications were available, although we did conduct a sub-analysis including diabetes duration and additionally adjusted for comorbidity. Finally, diabetes was self-reported which could have resulted in misclassification. Despite these limitations, this populationbased study with relatively high response is the first to prospectively address differences in HRQoL between CRCDM+ and $\mathrm{CRCDM}-$ patients and the impact of lifestyle.

In conclusion, this study showed that $\mathrm{CRCDM}+$ patients reported lower prospectively measured HRQoL as compared to CRCDM- patients; however, these differences disappeared after adjustments for lifestyle and other comorbidities. These results suggest that lifestyle factors and comorbidity might explain the difference in HRQoL between $\mathrm{CRCM}+$ and CRCDM- patients, although residual confounding cannot be excluded. As BMI, MVPA, smoking, and alcohol use were all independently associated with HRQoL, this study underlines the importance of improving lifestyle behaviors among CRC patients, either with or without diabetes.

Acknowledgments We thank all survivors and their doctors for their participation in the study. Special thanks to Dr. M van Bommel for her availability as an independent advisor and willingness to answer survivors' queries. In addition, we thank the following hospitals for their cooperation: Amphia Hospital (Breda), Bernhoven Hospital (Veghel and Oss), Catharina Hospital (Eindhoven), Elkerliek Hospital (Helmond), Jeroen Bosch Hospital ('s Hertogenbosch), Maxima Medical Center (Eindhoven and Veldhoven), St Anna Hospital (Geldrop), St Elisabeth Hospital (Tilburg), Twee Steden Hospital (Tilburg and Waalwijk), and VieCuri Hospital (Venlo and Venray).

Compliance with ethical standards All procedures performed in studies involving human participants were in accordance with the ethical standards of the institutional and/or national research committee and with the 1964 Helsinki Declaration and its later amendments or comparable ethical standards.

Conflict of interest The authors declare that they have no competing interests.

Informed consent Informed consent was obtained from all individual participants included in the study.

Funding The present research was supported by a grant from the European Foundation for the Study of Diabetes (EFSD) to Lonneke V. van de Poll-Franse and Frans Pouwer. Melissa Thong is supported by a Social Psychology Fellowship from the Dutch Cancer Society (\#UVT20114960).

Open Access This article is distributed under the terms of the Creative Commons Attribution-NonCommercial 4.0 International License (http:// creativecommons.org/licenses/by-nc/4.0/), which permits any noncommercial use, distribution, and reproduction in any medium, provided you give appropriate credit to the original author(s) and the source, provide a link to the Creative Commons license, and indicate if changes were made.

\section{References}

1. Parekh AK, Goodman RA, Gordon C, Koh HK (2011) Managing multiple chronic conditions: a strategic framework for improving health outcomes and quality of life. Public Health Rep 126(4):460471

2. World Health Organization (2011) Global status report on noncommunicable diseases 2010. World Health Organization, Geneva

3. Janssen-Heijnen MLG, Houterman S, Lemmens VEPP, Louwman MWJ, Maas HAAM, Coebergh JWW (2005) Prognostic impact of increasing age and co-morbidity in cancer patients: a population- 
based approach. Crit Rev Oncol Hematol 55(3):231-240. doi:10. 1016/j.critrevonc.2005.04.008

4. Larsson SC, Orsini N, Wolk A (2005) Diabetes mellitus and risk of colorectal cancer: a meta-analysis. J Natl Cancer Inst 97(22):16791687. doi:10.1093/jnci/dji375

5. Stein KB, Snyder CF, Barone BB, Yeh H-C, Peairs KS, Derr RL, Wolff AC, Brancati FL (2010) Colorectal cancer outcomes, recurrence, and complications in persons with and without diabetes mellitus: a systematic review and meta-analysis. Dig Dis Sci 55(7):1839-1851. doi:10.1007/s10620-009-0944-8

6. Bowker SL, Pohar SL, Johnson JA (2006) A cross-sectional study of health-related quality of life deficits in individuals with comorbid diabetes and cancer. Health Qual Life Outcomes 4:17. doi:10.1186/ 1477-7525-4-17

7. Hershey DS, Given B, Given C, Von Eye A, You M (2012) Diabetes and cancer: impact on health-related quality of life. Oncol Nurs Forum 39(5):449-457. doi:10.1188/12.ONF.449-457

8. Latini DM, Chan JM, Cowan JE, Arredondo SA, Kane CJ, Penson DF, DuChane J, Carroll PR (2006) Health-related quality of life for men with prostate cancer and diabetes: a longitudinal analysis from CaPSURE. Urology 68(6):1242-1247. doi:10.1016/j.urology. 2006.08.1096

9. Mols F, Aquarius AE, Essink-Bot ML, Aaronson NK, Kil PJ, van de Poll-Franse LV (2008) Does diabetes mellitus as a comorbid condition affect the health-related quality of life in prostate cancer survivors? Results of a population-based observational study. BJU Int 102(11):1594-1600. doi:10.1111/j.1464-410X.2008.07812.x

10. Vissers PA, Thong MS, Pouwer F, den Oudsten BL, Nieuwenhuijzen GA, van de Poll-Franse LV (2014) The individual and combined effect of colorectal cancer and diabetes on health-related quality of life and sexual functioning: results from the PROFILES registry. Support Care Cancer. doi:10.1007/s00520-014-2292-2

11. Onitilo AA, Donald M, Stankowski RV, Engel JM, Williams G, Doi SA (2013) Breast and prostate cancer survivors in a diabetic cohort: results from the Living with Diabetes Study. Clin Med Res 11(4): 210-218. doi:10.3121/cmr.2013.1156

12. Thong MS, van de Poll-Franse LV, Hoffman RM, Albertsen PC, Hamilton AS, Stanford JL, Penson DF (2011) Diabetes mellitus and health-related quality of life in prostate cancer: 5 -year results from the Prostate Cancer Outcomes Study. BJU Int 107(8):1223-1231. doi:10.1111/j.1464-410X.2010.09861.x

13. Grimmett C, Bridgewater J, Steptoe A, Wardle J (2011) Lifestyle and quality of life in colorectal cancer survivors. Qual Life Res 20(8):1237-1245. doi:10.1007/s11136-011-9855-1

14. Schlesinger S, Walter J, Hampe J, von Schonfels W, Hinz S, Kuchler T, Jacobs G, Schafmayer C, Nothlings U (2014) Lifestyle factors and health-related quality of life in colorectal cancer survivors. Cancer Causes Control 25(1):99-110. doi:10.1007/ s10552-013-0313-y

15. Blanchard CM, Courneya KS, Stein K, American Cancer Society's SCS, II (2008) Cancer survivors' adherence to lifestyle behavior recommendations and associations with health-related quality of life: results from the American Cancer Society's SCS-II. J Clin Oncol 26(13):2198-2204. doi:10.1200/JCO.2007.14.6217

16. Li C, Ford ES, Mokdad AH, Jiles R, Giles WH (2007) Clustering of multiple healthy lifestyle habits and health-related quality of life among U.S. adults with diabetes. Diabetes Care 30(7):1770-1776. doi:10.2337/dc06-2571

17. Husson O, Mols F, Ezendam NP, Schep G, van de Poll-Franse LV (2015) Health-related quality of life is associated with physical activity levels among colorectal cancer survivors: a longitudinal, 3-year study of the PROFILES registry. J Cancer Surviv. doi:10. 1007/s11764-014-0423-x

18. Lynch BM, Cerin E, Owen N, Hawkes AL, Aitken JF (2008) Prospective relationships of physical activity with quality of life among colorectal cancer survivors. J Clin Oncol 26(27):4480 4487. doi:10.1200/JCO.2007.15.7917

19. Jang S, Prizment A, Haddad T, Robien K, Lazovich D (2011) Smoking and quality of life among female survivors of breast, colorectal and endometrial cancers in a prospective cohort study. $\mathrm{J}$ Cancer Surviv 5(2):115-122. doi:10.1007/s11764-010-0147-5

20. Eckert K (2012) Impact of physical activity and bodyweight on health-related quality of life in people with type 2 diabetes. Diabetes Metab Syndr Obes 5:303-311. doi:10.2147/DMSO. S34835

21. Green AJ, Fox KM, Grandy S (2011) Impact of regular exercise and attempted weight loss on quality of life among adults with and without type 2 diabetes mellitus. J Obes. doi:10.1155/2011/172073

22. van de Poll-Franse LV, Horevoorts N, van Eenbergen M, Denollet J, Roukema JA, Aaronson NK, Vingerhoets A, Coebergh JW, de Vries J, Essink-Bot ML, Mols F, Profiles Registry G (2011) The Patient Reported Outcomes Following Initial treatment and Long term Evaluation of Survivorship registry: scope, rationale and design of an infrastructure for the study of physical and psychosocial outcomes in cancer survivorship cohorts. Eur J Cancer 47(14): 2188-2194. doi:10.1016/j.ejca.2011.04.034

23. Demark-Wahnefried W, Aziz NM, Rowland JH, Pinto BM (2005) Riding the crest of the teachable moment: promoting long-term health after the diagnosis of cancer. J Clin Oncol 23(24):5814 5830. doi:10.1200/JCO.2005.01.230

24. Sangha O, Stucki G, Liang MH, Fossel AH, Katz JN (2003) The self-administered comorbidity questionnaire: a new method to assess comorbidity for clinical and health services research. Arthritis Care Res 49(2):156-163. doi:10.1002/art.10993

25. Pols MA, Peeters PH, Ocké MC, Slimani N, Bueno-de-Mesquita HB, Collette HJ (1997) Estimation of reproducibility and relative validity of the questions included in the EPIC Physical Activity Questionnaire. Int J Epidemiol 26(suppl 1):S181. doi:10.1093/ije/ 26.suppl_1.S181

26. Ainsworth BE, Haskell WL, Leon AS, Jacobs DR, Montoye HJ, Sallis JF, Paffenbarger RS (1993) Compendium of physical activities: classification of energy costs of human physical activities. Med Sci Sports Exerc 25(1):71-80

27. Ainsworth BE, Haskell WL, Whitt MC, Irwin ML, Swartz AM, Strath SJ, O'brien WL, Bassett DR, Schmitz KH, Emplaincourt PO, Jacobs DR, Leon AS (2000) Compendium of physical activities: an update of activity codes and MET intensities. Med Sci Sports Exerc 32(9):S498-S516

28. Buffart LM, Thong MSY, Schep G, Chinapaw MJM, Brug J, van de Poll-Franse LV (2012) Self-reported physical activity: its correlates and relationship with health-related quality of life in a large cohort of colorectal cancer survivors. PLoS One 7(5):e36164. doi:10. 1371/journal.pone.0036164

29. Aaronson NK, Ahmedzai S, Bergman B, Bullinger M, Cull A, Duez NJ, Filiberti A, Flechtner H, Fleishman SB, Haes JC, Kaasa S, Klee M, Osoba D, Razavi D, Rofe PB, Schraub S, Sneeuw K, Sullivan M, Takeda F (1993) The European Organization for research and treatment of cancer QLQ-C30: a quality-of-life instrument for use in international clinical trials in oncology. J Natl Cancer Inst 85(5):365-376. doi:10.1093/jnci/85.5.365

30. Fayers PM, Aaronson NK, Bjordal K, Sullivan M (1995) EORTC QLQ-C30 scoring manual. Brussels, Belgium 11:1-49

31. Vissers PA, Thong MS, Pouwer F, Zanders MM, Coebergh JW, van de Poll-Franse LV (2013) The impact of comorbidity on HealthRelated Quality of Life among cancer survivors: analyses of data from the PROFILES registry. J Cancer Surviv 7(4):602-613. doi: 10.1007/s11764-013-0299-1

32. Niu C, Eng L, Qiu X, Shen X, Espin-Garcia O, Song Y, Pringle D, Mahler M, Halytskyy O, Charow R, Lam C, Shani RM, Villeneuve J, Tiessen K, Brown MC, Selby P, Howell D, Jones JM, Xu W, Liu G, Alibhai SM (2015) Lifestyle behaviors in elderly cancer 
survivors: a comparison with middle-age cancer survivors. J Oncol Pract 11(4):e450-459. doi:10.1200/JOP.2014.002287

33. Deshpande AD, Harris-Hayes M, Schootman M (2008) Epidemiology of diabetes and diabetes-related complications. Phys Ther 88(11): 1254-1264. doi:10.2522/pti.20080020

34. Eckel RH, Grundy SM, Zimmet PZ (2005) The metabolic syndrome. Lancet 365(9468):1415-1428. doi:10.1016/S01406736(05)66378-7

35. Giovannucci E, Harlan DM, Archer MC, Bergenstal RM, Gapstur SM, Habel LA, Pollak M, Regensteiner JG, Yee D (2010) Diabetes and cancer: a consensus report. Diabetes Care 33(7):1674-1685. doi:10.2337/dc10-0666
36. Silver JK, Baima J (2013) Cancer prehabilitation: an opportunity to decrease treatment-related morbidity, increase cancer treatment options, and improve physical and psychological health outcomes. Am J Phys Med Rehabil 92(8):715-727. doi:10.1097/PHM. 0b013e31829b4afe

37. Kuczmarski MF, Kuczmarski RJ, Najjar M (2001) Effects of age on validity of self-reported height, weight, and body mass index: findings from the third national health and nutrition examination survey, 1988-1994. J Am Diet Assoc 101(1):28-34. doi:10.1016/S00028223(01)00008-6 